\title{
MWRRET Value-Added Product: The Retrieval of Liquid Water Path and Precipitable Water Vapor from Microwave Radiometer (MWR) Datasets
}

\author{
K.L. Gaustad \\ D.D. Turner
}

September 2007

Work supported by the U.S. Department of Energy,

Office of Science, Office of Biological and Environmental Research 


\section{DISCLAIMER}

This report was prepared as an account of work sponsored by the U.S. Government. Neither the United States nor any agency thereof, nor any of their employees, makes any warranty, express or implied, or assumes any legal liability or responsibility for the accuracy, completeness, or usefulness of any information, apparatus, product, or process disclosed, or represents that its use would not infringe privately owned rights. Reference herein to any specific commercial product, process, or service by trade name, trademark, manufacturer, or otherwise, does not necessarily constitute or imply its endorsement, recommendation, or favoring by the U.S. Government or any agency thereof. The views and opinions of authors expressed herein do not necessarily state or reflect those of the U.S. Government or any agency thereof. 


\begin{abstract}
This report provides a short description of the Atmospheric Radiation Measurement (ARM) microwave radiometer (MWR) RETrievel (MWRRET) Value-Added Product (VAP) algorithm. This algorithm utilizes complimentary physical and statistical retrieval methods and applies brightness temperature offsets to reduce spurious liquid water path (LWP) bias in clear skies resulting in significantly improved precipitable water vapor (PWV) and LWP retrievals. We present a general overview of the technique, input parameters, output products, and describe data quality checks. A more complete discussion of the theory and results is given in Turner et al. (2007b).
\end{abstract}




\section{Contents}

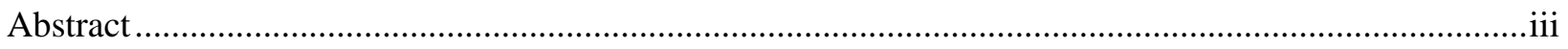

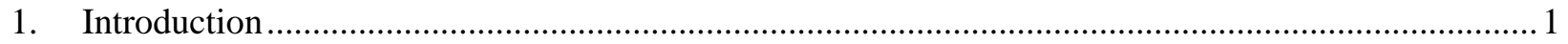

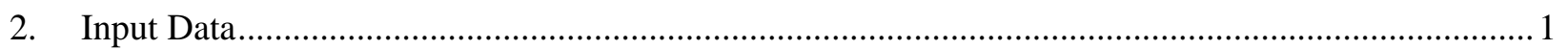

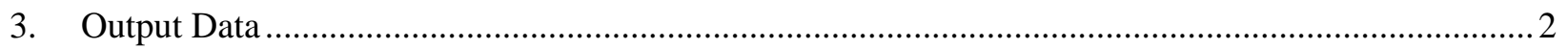

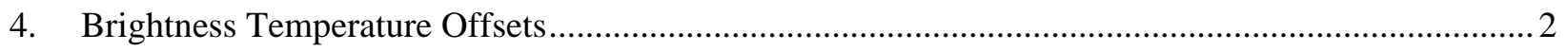

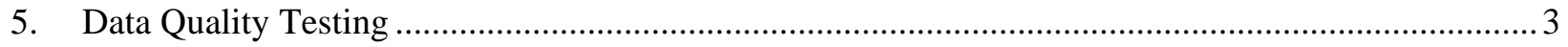

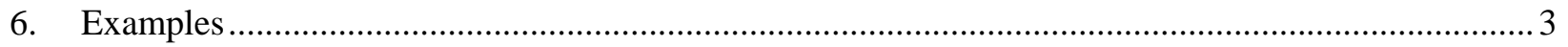

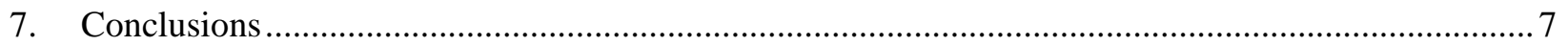

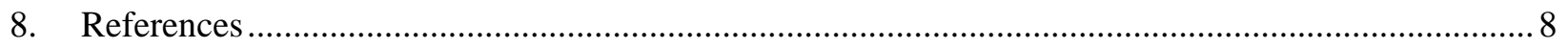

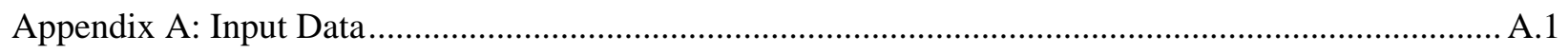

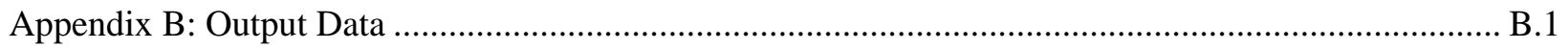

Figures

1 Quicklook image using standard y-axis ranges where the physical retrievals are performed only for samples corresponding to the sonde launch times........................................................... 4

2 Quicklook image using dynamically sized y-axis where the physical retrievals are performed only for samples corresponding to the sonde launch times. ........................................... 5

3 Quicklook image using standard y-axis ranges where the physical retrievals are performed for a 30 -minute period following the sonde launch times........................................................... 6

$4 \quad$ Quicklook image using dynamically sized y-axis where the physical retrievals are performed for a 30-minute period following the sonde launch times.

\section{Tables}

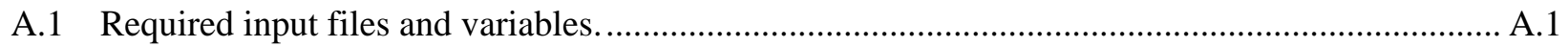

A.2 Optional input files and variables.................................................................................................. A.4

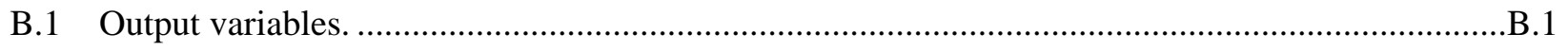




\section{Introduction}

The Atmospheric Radiation Measurement (ARM) Program deploys microwave radiometers (MWR) that observe downwelling radiation at 23.8 and $31.4 \mathrm{GHz}$ to each of its data gathering sites. Retrievals of precipitable water vapor (PWV) and liquid water path (LWP), crucial elements in building a better understanding of radiative transfer in the atmosphere and clouds, are generated from a retrieval algorithm that resides on the MWR instrument computers. These instrument-based retrieval algorithms use a statistical methodology based on site-dependent monthly retrieval coefficients (Liljegren and Lesht 1996). While very fast, this inversion approach can have large errors if atmospheric conditions are significantly different from the conditions captured in the retrieval coefficients, the retrieval coefficients are sitespecific and cannot be applied to other locations, and the method does not address the systematic clearsky biases in the retrieved LWP (Turner et al. 2004). The MWR RETrieval (MWRRET) Value-Added Product (VAP) was developed to address the inherent short-falls in the original (orig) statistical retrieval algorithm that resides on the MWR. It does this through the use of complementary physical and statistical retrieval methods and the application of brightness temperature offsets. While too computationally intensive to use to process all MWR data samples, the physical retrieval algorithm (phys) produces the most accurate retrievals possible when the atmospheric temperature profile and an estimate of the distribution of water vapor and liquid water are known. For general processing, the statistical retrieval method (stat2) should be used. The stat2 algorithm utilizes more information than the 'orig' algorithm resulting in improved accuracy and, through the use of surface meteorological data, allows the retrieval to be site independent if the initial dataset used to develop the statistical relationship includes a range of atmospheric state conditions observed in different locations.

The details of this algorithm have been published in Turner et al. (2007b). We refer the readers to this article for more detailed information about the algorithm applied in this VAP.

\section{Input Data}

The input data required by this VAP include observed brightness temperatures, PWV and LWP retrievals produced by the 'orig' algorithm residing on the MWR instrument, and surface meteorology observations. The actual datastream from which the surface met data is extracted is a function of the site and facility that is being processed. Appendix A, Table A.1, lists the datastreams and correlating input and quality check fields that are required to run the MWRRET VAP. Optional inputs such as reflectivity, cloud base height, and vertical profiles of atmospheric conditions are presented in Appendix A, Table A.2. While the VAP will run without the SONDE profiles, they should be used when available. The specific sonde platform used as input is selected based on data availability. If more than one sonde platform is available for a given day, the input is chosen based on a prioritized list with 'wnpn.b1' the first choice, followed by 'wrpn.a1', 'wrpn.b1', 'wnpn.a1', and 'wrpr.a1'. Whether or not to use the cloud base height from the Belfort laser ceilometer (BLC), Vaisala ceilometer (VCEIL), or active remote sensing of cloud locations (ARSCL) as input is specified at the command line and is left to the VAP operator's discretion. 


\section{Output Data}

The primary data products of the MWRRET VAP are best estimates of the PWV and LWP values. When run in real time on the ARM production system, the best estimates are equal to the retrievals produced by the stat2 statistical retrieval algorithm. As part of the yearly reprocessing discussed in the following section on annual reprocessing to determine brightness temperature offsets, the best estimates are updated to represent an optimized blend of both the stat2(statistical) and phys(physical) retrieval methods. In addition to the best estimate values, the PWV and LWP values for the orig, stat2, and phys methods are included in the output as are supporting surface meteorological and MWR input data used in their calculations. Global attributes read from the MWR input file are propagated to the output and new attributes are defined for the static $T_{b}$ offset bias values and, if so, when these offsets were created. A complete list of all the output fields and a brief description of each is given in Appendix B.

One file is created for each day named with the following convention:

XXXmwrret1liljclouFF.c1.YYYYMMDD.hhmmss

where:

$\mathrm{XXX}=$ the location of the instrument (nsa, sgp, twp, pye, etc.)

mwrret1liljclou $=$ identifies that this is Turner's version 1 MWRRET VAP

$\mathrm{FF}=$ facility (e.g., C1)

YYYYMMDD = year, month, and day

hhmmss $=$ hour, minute, second

The VAP generates a quicklook output file within which three plots are presented: (1) MWR brightness temperature values including data quality status, (2) PWV calculated by the 'orig', 'stat2', and 'phys' retrieval methods, and (3) LWP calculated by the 'orig', 'stat2', and 'phys' retrieval methods. Two versions of this quicklook product are created. One with a standard fixed y-axis for each of the plots, and another with a dynamically resized y-axis to automatically adjust for periods with relatively flat brightness temperature and retrieval values. The output file for the standard and dynamically resized quicklooks use the following naming convention: XXXmwrret1liljclouC1.YYYYMMDD.png XXXmwrret1liljclouC1.YYYYMMDD.dynamic.png

\section{Brightness Temperature Offsets}

Offsets to brightness temperature can be applied to both the 23.8-GHz and 31.4-GHz channels. The 23.8$\mathrm{GHz}$ offsets, which reduce bias in the retrieved PWV, are determined once per year for each site and facility and as such are referred to as 'static' offsets. When running in real time on the ARM production system, static $T_{b}$ offsets are not applied. At the end of each year, the data from the year are post-analyzed and the appropriate static offset value at $23.8 \mathrm{GHz}$ is determined. The $\mathrm{T}_{\mathrm{b}}$ offset configuration file is updated with the value of newly determined static offsets and the data is reprocessed to apply the offsets.

As previously discussed, small biases in the retrieved LWP (from $+/-5$ to $30 \mathrm{~g} / \mathrm{m} 2$ ) can be retrieved from the MWR in clear sky scenes when the LWP should be zero (within the retrieval uncertainty). These LWP 
biases, which can exist for long periods of time, result in significant error in radiative transfer calculations (e.g., Turner et al. 2007a). To reduce the size of the LWP biases, the VAP also can be configured to subtract small offsets from the observed brightness temperature at $31.4 \mathrm{GHz}$ so that, statistically, a LWP of zero in clear skies is obtained. To capture the impact of calibration changes over time, these 'variable' offsets are computed directly from the data for a specified number of cases, which are kept in a rolling database of offsets stored in the $\mathrm{T}_{b}$ offset configuration file. The VAP computes the mean value from the middle two quartiles of the offset data to determine the value to subtract from the observation. This offset is added to the rolling database, and the oldest offset value is removed to maintain a fixed number of points in the rolling database. The variable offset is applied only to the 31.4-GHz channel. More details on the $\mathrm{T}_{\mathrm{b}}$ offsets are given in Turner et al. 2007b.

\section{Data Quality Testing}

All quality flags associated with the input fields are propagated to the output. Additional quality tests, developed by Jim Liljegren, are applied to the MWR brightness temperatures to identify periods where these values experience sudden abnormal instantaneous changes in their values. These additional brightness temperature tests relate to instrument health as determined by examination of available data. Tests applied include identification of thermal stabilization issues, detection of spikes, and invalid optical depths. Quality control (QC) tests also were developed for the non-best estimate PWV and LWP fields calculated by the VAP.

\section{Examples}

Figure 1 shows the standard quicklook product for March 14, 2000. For this day, the VAP was run with the option of performing physical retrievals only at the samples that correspond to the sonde launch. Using command line options the MWRRET VAP allows the user to specify whether and how to perform the physical retrievals for a given day. Possible scenarios include running the physical retrieval for each sample in the day, for every nth sample, for 30 minutes after each sonde launch, or only for samples that correspond to a sonde launch. While difficult to see the single phys_retrieval sample indicated in blue at each launch, it is inherent in the plot that the physical retrieval was run because the 'pwv_phys', 'Iwp_phys', 'sonde_launch' are defined in the PWV and LWP legends and the sonde launch times are indicated in the PWV plot.

In Figure 2, the dynamically sized version of March 14, 2000, the blue line representing the physical retrieval sample value is evident just above the stat 2 and orig values at the time correlating to the last sonde launch of the day.

Figure 3 illustrates how the data quality test results are folded into the brightness temperature plot. The qc instrument health tests that failed, 'warm up' and 'over heat' are indicated at the right of the plot, with the affected samples marked with corresponding color bars. It is also a day with relatively flat brightness temperatures and retrievals.

Figure 4 is the companion dynamically sized plot for the same day. For this day, the physical retrievals were run for a 30-minute set of samples immediately following the sonde launch. 
PWVLWP1LILJCLOU data for sgp C1, 14 Mar 2000
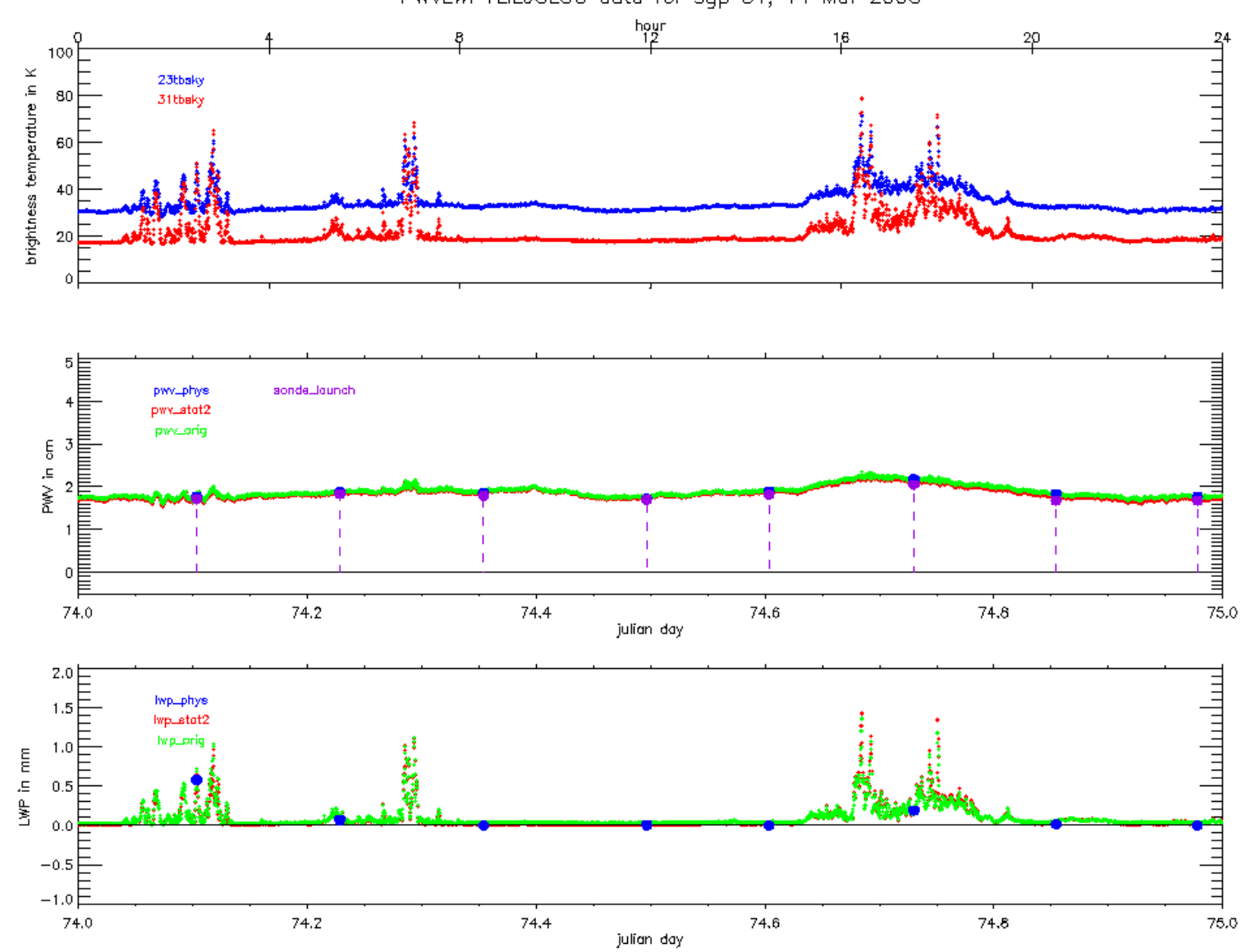

Figure 1: Quicklook image using standard y-axis ranges where the physical retrievals are performed only for samples corresponding to the sonde launch times. 

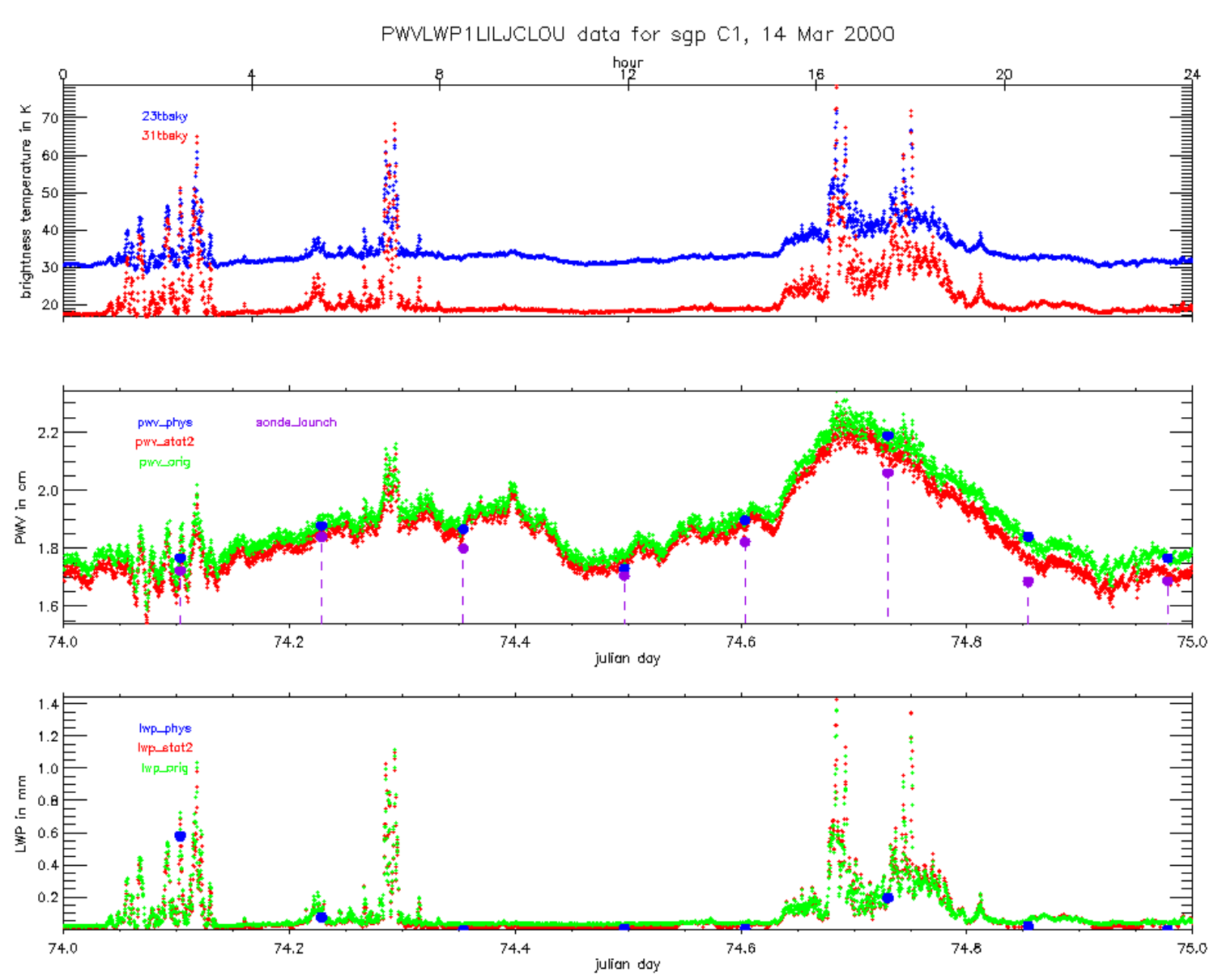

Figure 2: Quicklook image using dynamically sized y-axis where the physical retrievals are performed only for samples corresponding to the sonde launch times. 

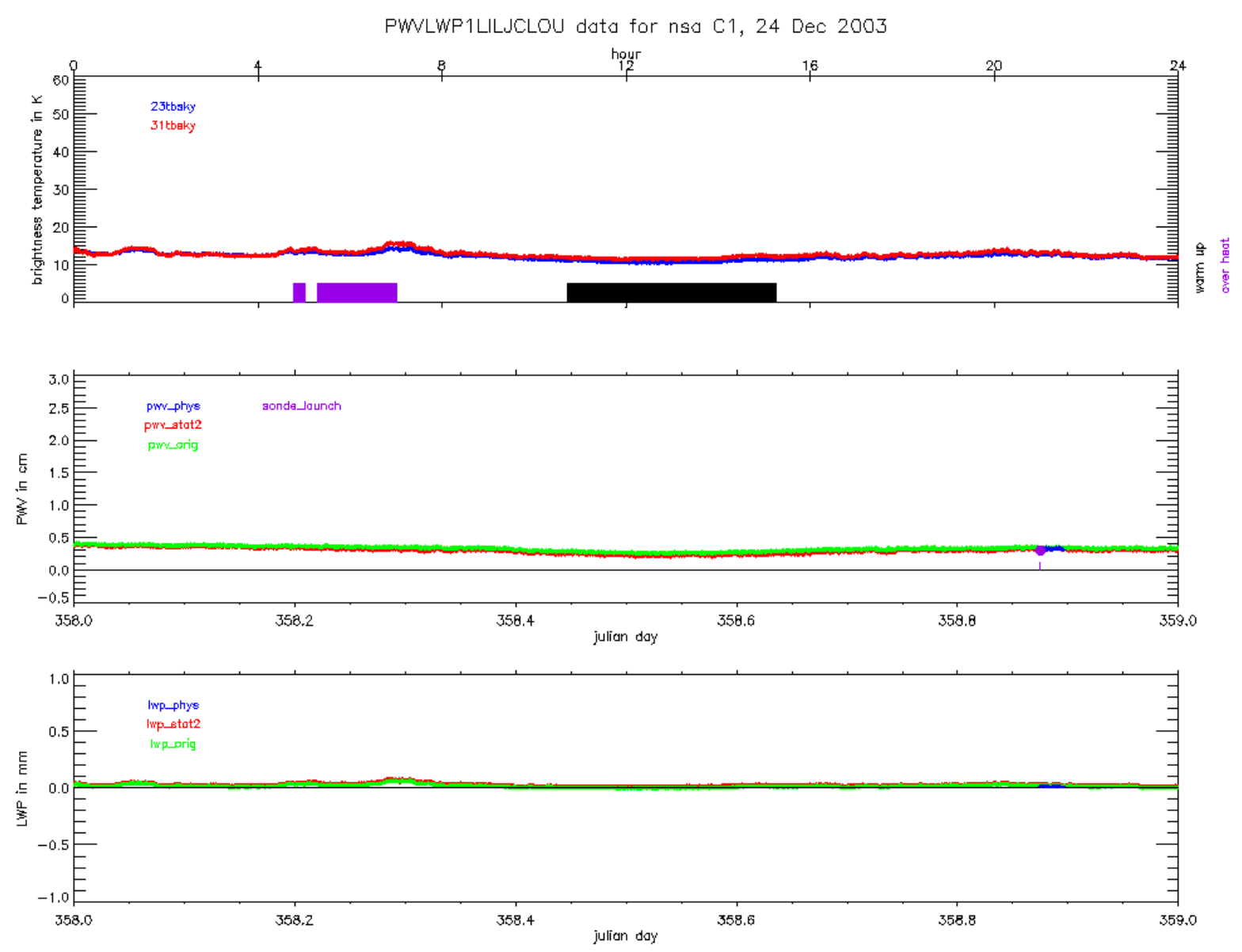

Figure 3: Quicklook image using standard y-axis ranges where the physical retrievals are performed for a 30-minute period following the sonde launch times. 

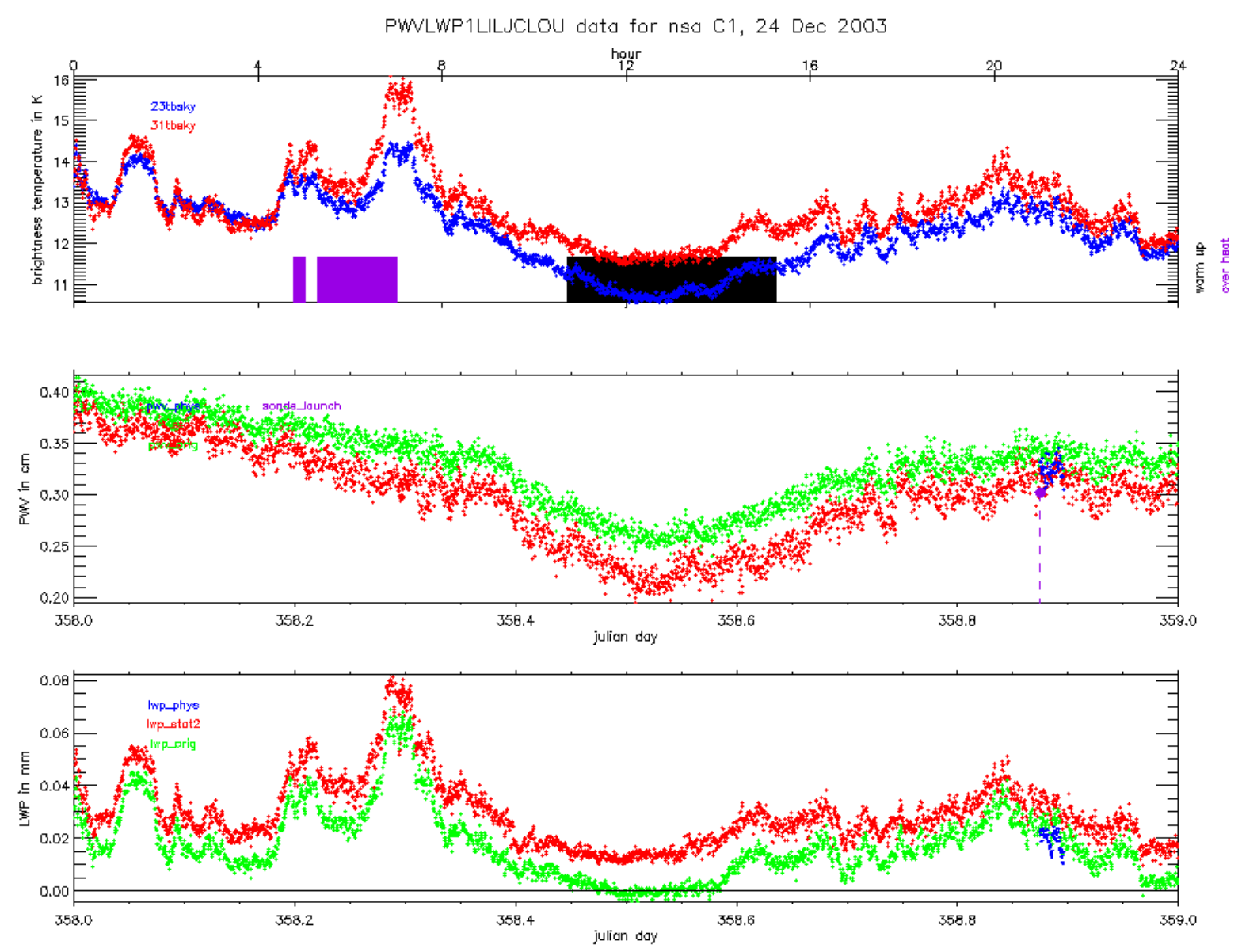

Figure 4: Quicklook image using dynamically sized y-axis where the physical retrievals are performed for a 30-minute period following the sonde launch times.

\section{Conclusions}

Measurements of both cloud properties and radiative fluxes are needed to improve global climate models (GCMs) and subsequently their prediction of future climates. Accurate measurements of PWV and LWP values support these goals through validating radiative transfer models, specifying atmospheric and cloud properties, and increasing the understanding of the first aerosol indirect effect. By providing two improved retrieval methods and applying brightness temperature offsets to reduce spurious LWP bias in clear skies, the MWRRET algorithm provides significantly better retrievals of PWV and LWP from the ARM 2-channel microwave radiometers compared to the original retrieval method included in the ARM MWR ingest data product. 


\section{References}

Liljegren, JC, and BM Lesht. 1996. "Measurements of integrated water vapor and cloud liquid water from microwave radiometers at the DOE ARM cloud and radiation testbed in the U.S. Southern Great Plains.” In Proceedings of the International Geoscience and Remote Sensing Symposium (IGARSS), Lincoln, Nebraska, pp.1675-1677.

Turner, DD, and KL Gaustad. 2004. "Improved PWV and LWP Retrievals from the Microwave Radiometer for ARM.” In Proceedings of the Fourteenth Atmospheric Radiation Measurement (ARM) Science Team Meeting, U.S. Department of Energy, Richland, Washington. Available URL: http://www.arm.gov/publications/proceedings/conf14/author.stm

Turner, DD, AM Vogelmann, R Austin, JC Barnard, K Cady-Pereira, C Chiu, SA Clough, CJ Flynn, MM Khaiyer, JC Liljegren, K Johnson, B Lin, CN Long, A Marshak, SY Matrosov, SA McFarlane, MA Miller, Q Min, P Minnis, W O'Hirok, Z Wang, and W Wiscombe. 2007a. "Optically thin liquid water clouds: Their importance and our challenge.” Bulletin of the American Meteorological Society, 88, 191204.

Turner, DD, SA Clough, JC Liljegren, EE Clouthiaux, K Cady-Pereira, and KL Gaustad. 2007b. "Retrieving liquid water path and precipitable water vapor from the Atmospheric Radiation Measurement (ARM) microwave radiometers.” IEEE Transactions on Geoscience and Remote Sensing, in press. 


\section{Appendix A: Input Data}

Table A.1 lists the input datastreams and fields required to run the MWRRET VAP.

Talbe A.2 lists the input datastreams and fields that are optional inputs to the MWRRET VAP.

Table A.1: Required input files and variables.

\begin{tabular}{|c|c|c|c|}
\hline Datastream & Variable Name & Variable Long Name & Units \\
\hline \multirow{17}{*}{$\begin{array}{l}X X X m w r l o s F F . b 1 \\
X X X \text { is all sites }\end{array}$} & tbsky23 & 23.8 GHz sky brightness temperature & $\mathrm{K}$ \\
\hline & tbsky31 & 31.4 GHz sky brightness temperature & K \\
\hline & vap & Total water vapor along LOS path & $\mathrm{cm}$ \\
\hline & liq & Total liquid water along LOS path & $\mathrm{cm}$ \\
\hline & sky23 & $23.8 \mathrm{GHz}$ sky signal & counts \\
\hline & sky31 & 31.4 GHz sky signal & counts \\
\hline & teflon_window_correction_coef_23 & global attribute - no long name & unitless \\
\hline & teflon_window_correction_coef_31 & global attribute - no long name & unitless \\
\hline & mean_atmos_radiating_temp_23 & global attribute - no long name & unitless \\
\hline & mean_atmos_radiaing_temp_31 & global attribute - no long name & unitless \\
\hline & cosmic_background_temperature & global attribute - no long name & unitless \\
\hline & vapor_retrieval_coefficient_0 & global attribute - no long name & unitless \\
\hline & vapor_retrieval_coefficient_0 & global attribute - no long name & unitless \\
\hline & vapor_retrieval_coefficient_1 & global attribute - no long name & unitless \\
\hline & liquid_retrieval_coefficient_0 & global attribute - no long name & unitless \\
\hline & liquid_retrieval_coefficient_1 & global attribute - no long name & unitless \\
\hline & liquid_retrieval_coefficient_2 & global attribute - no long name & unitless \\
\hline \multirow{9}{*}{$\begin{array}{l}X X X m w r l o s F F . b 1 \\
X X X \text { is not a parsl } \\
\text { site }\end{array}$} & bb23 & 23.8 GHz Blackbody signal & counts \\
\hline & bb31 & 31.4 GHz Blackbody signa & counts \\
\hline & bbn23 & $\begin{array}{l}23.8 \mathrm{GHz} \text { blackbody+noise injection } \\
\text { signal }\end{array}$ & counts \\
\hline & bbn31 & $\begin{array}{l}\text { 31.4 GHz blackbody+noise injection } \\
\text { signal }\end{array}$ & counts \\
\hline & tkbb & Blackbody kinetic temperature & K \\
\hline & tkxc & Mixer kinetic (physical) temperature & $\mathrm{K}$ \\
\hline & tnd_nom23 & $\begin{array}{l}\text { Noise injection temp at nominal } \\
\text { temperature at } 23.8 \mathrm{GHz}\end{array}$ & K \\
\hline & tnd_nom31 & $\begin{array}{l}\text { Noise injection temp at nominal } \\
\text { temperature at } 31.4 \mathrm{GHz}\end{array}$ & K \\
\hline & tc23 & $\begin{array}{l}\text { Temperature correction coefficient at } \\
23.8 \mathrm{GHz}\end{array}$ & $\mathrm{K} / \mathrm{K}$ \\
\hline
\end{tabular}


Table A.1: Required input files and variables (cont.).

\begin{tabular}{|c|c|c|c|}
\hline Datastream & Variable Name & Variable Long Name & Units \\
\hline \multirow{5}{*}{$\begin{array}{l}X X X m w r l o s F F . b 1 \\
X X X \text { is not a parsl } \\
\text { site } \\
\text { (cont.) }\end{array}$} & tc31 & $\begin{array}{l}\text { Temperature correction coefficient at } \\
31.4 \mathrm{GHz}\end{array}$ & $\mathrm{K} / \mathrm{K}$ \\
\hline & qc_tbsky23 & $\begin{array}{l}\text { Quality check results on field: } 23.8 \\
\text { GHz sky brightness temperature }\end{array}$ & unitless \\
\hline & qc_tbsky31 & $\begin{array}{l}\text { Quality check results on field: } 31.4 \\
\text { GHz sky brightness temperature }\end{array}$ & unitless \\
\hline & qc_vap & $\begin{array}{l}\text { Quality check results on field: Total } \\
\text { water vapor along LOS path }\end{array}$ & unitless \\
\hline & qc_liq & $\begin{array}{l}\text { Quality check results on field: Total } \\
\text { liquid water along LOS path }\end{array}$ & unitless \\
\hline \multirow{4}{*}{$\begin{array}{l}X X X 1 \text { twrmwrFF.c1 } \\
X X X \text { is sgp } \\
\text { FF is C1 or E13 }\end{array}$} & pres_02 & Barometric pressure at $2 \mathrm{~m}$ & $\mathrm{mb}$ \\
\hline & temp_02 & Temperature at $2 \mathrm{~m}$ & $\operatorname{deg} C$ \\
\hline & vap_pres_02m & Vapor pressure at $2 \mathrm{~m}$ & $\mathrm{mb}$ \\
\hline & rh_02 & Relative humidity at $2 \mathrm{~m}$ & $\%$ \\
\hline \multirow{8}{*}{$\begin{array}{l}X X X \text { thwapsFF.b1 } \\
\text { where } X X X \text { is sgp } \\
F F \text { is not } C 1 \text { or } E 13\end{array}$} & pres & Pressure & $\mathrm{hPa}$ \\
\hline & temp & Temperature & C \\
\hline & vap_res & Vapor Pressure & $\mathrm{kPa}$ \\
\hline & rh & Relative Humidity & $\%$ \\
\hline & qc_press & $\begin{array}{l}\text { Quality check results on field: } \\
\text { Pressure }\end{array}$ & unitless \\
\hline & qc_temp & $\begin{array}{l}\text { Quality check results on field: } \\
\text { Temperature }\end{array}$ & unitless \\
\hline & qc_vap_pres & $\begin{array}{l}\text { Quality check results on field: Vapor } \\
\text { Pressure }\end{array}$ & unitless \\
\hline & qc_rh & $\begin{array}{l}\text { Quality check results on field: Vapor } \\
\text { Pressure }\end{array}$ & unitless \\
\hline \multirow{7}{*}{$\begin{array}{l}\text { XXXsmet60sFF.b1 } \\
X X X \text { is twp or pye } \\
\text { and not a parsl site }\end{array}$} & atmos_pressure & Pressure & \\
\hline & temp_mean & Temperature & \\
\hline & vappress_mean & Vapor Pressure & \\
\hline & relh_mean & Relative Humidity & \\
\hline & qc_atmos_pressure & $\begin{array}{l}\text { Quality check results on field: } \\
\text { Pressure }\end{array}$ & unitless \\
\hline & qc_temp_mean & $\begin{array}{l}\text { Quality check results on field: } \\
\text { Temperature }\end{array}$ & unitless \\
\hline & qc relh mean & $\begin{array}{l}\text { Quality check results on field: Vapor } \\
\text { Pressure }\end{array}$ & unitless \\
\hline
\end{tabular}


Table A.1: Required input files and variables (cont.).

\begin{tabular}{|c|c|c|c|}
\hline Datastream & Variable Name & Variable Long Name & Units \\
\hline \multirow{8}{*}{$\begin{array}{l}X X X \text { mettwr4hFF.b1 } \\
X X X \text { is nsa } \\
\text { FF is C1 }\end{array}$} & AtmPress & Atmospheric Pressure & $\mathrm{kPa}$ \\
\hline & T2M_AVG & $2 \mathrm{~m}$ Average Temperature & C \\
\hline & VP2M_AVG & $\begin{array}{l}\text { 2m Average Calculated Vapor } \\
\text { Pressure }\end{array}$ & $\mathrm{kPa}$ \\
\hline & RH2M_AVG & 2m Average Relative Humidity & $\%$ \\
\hline & qc_AtmPress & $\begin{array}{l}\text { Quality check results on field: } \\
\text { Atmospheric Pressure }\end{array}$ & unitless \\
\hline & qc_T2M_AVG & $\begin{array}{l}\text { Quality check results on field: } 2 \mathrm{~m} \\
\text { Average Temperature }\end{array}$ & unitless \\
\hline & qc_VP2M_AVG & $\begin{array}{l}\text { Quality check results on field: } 2 \mathrm{~m} \\
\text { Average Calculated Vapor Pressure }\end{array}$ & unitless \\
\hline & qc_RH2M_AVG & $\begin{array}{l}\text { Quality check results on field: } 2 \mathrm{~m} \\
\text { Average Relative Humidity }\end{array}$ & unitless \\
\hline \multirow{8}{*}{ 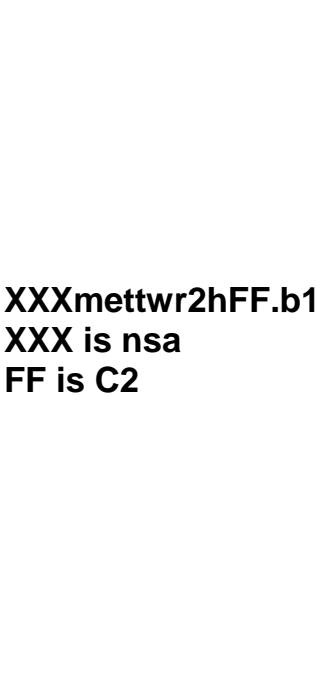 } & AtmPress & Atmospheric Pressure & $\mathrm{kPa}$ \\
\hline & T2m_AVG & $2 \mathrm{~m}$ Average Temperature & C \\
\hline & VP2m_AVG & $\begin{array}{l}\text { 2m Average Calculated Vapor } \\
\text { Pressure }\end{array}$ & $\mathrm{kPa}$ \\
\hline & RH2m_AVG & 2m Average Relative Humidity & $\%$ \\
\hline & qc_AtmPress & $\begin{array}{l}\text { Quality check results on field: } \\
\text { Atmospheric Pressure }\end{array}$ & unitless \\
\hline & qc_T2m_AVG & $\begin{array}{l}\text { Quality check results on field: } 2 \mathrm{~m} \\
\text { Average Temperature }\end{array}$ & unitless \\
\hline & qc_PV2m_AVG & $\begin{array}{l}\text { Quality check results on field: } 2 \mathrm{~m} \\
\text { Average Calculated Vapor Pressure }\end{array}$ & unitless \\
\hline & qc_RH2m_AVG & $\begin{array}{l}\text { Quality check results on field: } 2 \mathrm{~m} \\
\text { Average Relative Humidity }\end{array}$ & unitless \\
\hline \multirow{3}{*}{$\begin{array}{l}X X X \text { mettwrFF.b1 } \\
X X X \text { is a parsl site }\end{array}$} & pressure & Surface atmospheric pressure & $\begin{array}{l}\text { hectoPas } \\
\text { cals } \\
\text { (milibars) }\end{array}$ \\
\hline & temperature & $\begin{array}{l}\text { Surface atmospheric dry bulb } \\
\text { temperature }\end{array}$ & $\begin{array}{l}\text { degrees } \\
\text { Celcius }\end{array}$ \\
\hline & rh & $\begin{array}{l}\text { Surface atmospheric relative } \\
\text { humidity }\end{array}$ & Percent \\
\hline
\end{tabular}


Table A.2: Optional input files and variables.

\begin{tabular}{|c|c|c|c|}
\hline Datastream & Variable Name & Variable Long Name & Units \\
\hline \multirow{4}{*}{ XXXsonde<type $>$ FF.b1 } & alt & altitude & $\begin{array}{l}\text { meters } \\
\text { above } \\
\text { Mean Sea } \\
\text { Level }\end{array}$ \\
\hline & pres & Pressure & $\mathrm{hPa}$ \\
\hline & tdry & Dry Bulb Temperature & C \\
\hline & rh & Relative Humidityl & $\%$ \\
\hline \multirow{3}{*}{ XXXarscl1clothFF.c1 } & CloudBaseBestEstimate & $\begin{array}{l}\text { Cloud Base Height Best } \\
\text { Estimate }\end{array}$ & m AGL \\
\hline & Heights & Height of Measured Value & m AGL \\
\hline & ReflectivityBestEstimate & $\begin{array}{l}\text { MCR Best Estimate of } \\
\text { Hydrometeor Reflectivity }\end{array}$ & $\begin{array}{l}\mathrm{dBZ} \\
(X 100)\end{array}$ \\
\hline \multirow{2}{*}{$\begin{array}{l}\text { XXXvceil25kFF.a1 } \\
\text { XXXvceil25kFF.b1 }\end{array}$} & first_cbh & $\begin{array}{l}\text { Lowest cloud base height } \\
\text { detected }\end{array}$ & $\mathrm{m}$ \\
\hline & detection_status & Detection status. & unitless \\
\hline XXXblcFF.a1 & cloud1 & $\begin{array}{l}\text { Base height of lowest cloud } \\
\text { detected by threshold } \\
\text { algorithm }\end{array}$ & $\begin{array}{l}\text { m above } \\
\text { ground } \\
\text { level }\end{array}$ \\
\hline
\end{tabular}

The names of the input datastreams have the format:

XXX $<$ plat $>$ FF. $<$ level $>$.YYYYMMDD.hhmmss

Where:

$\mathrm{XXX}=$ the locations of the instrument (nsa, sgp, twp, pye, etc.)

$<$ plat $>=$ the main instrument name

$\mathrm{FF}=$ facility (e.g., C1)

$<$ level $>\quad=$ data level, can be a1

YYYYMMDD = year, month, and day

hhmmss = hour, minute, second 


\section{Appendix B: Output Data}

Table B.1 lists the fields found in the MWRRET output NetCDF files.

Table B.1: Output variables.

\begin{tabular}{|c|c|c|}
\hline Fieldname & Description & Units \\
\hline base_time & Base Time in Epoch & $\begin{array}{l}\text { seconds } \\
\text { since } \\
\text { 1970/01/01 } \\
\text { 00:00:00 }\end{array}$ \\
\hline time_offset & Time offset from base_time & $\begin{array}{l}\text { seconds } \\
\text { since } \\
\text { base_time }\end{array}$ \\
\hline time & Time offset from midnight & $\begin{array}{l}\text { seconds } \\
\text { since } \\
\text { midnight }\end{array}$ \\
\hline hour & Hour of the day & UTC \\
\hline level_height & Level height & $\mathrm{km}$ AGL \\
\hline be_pwv & Precipitable water vapor best-estimate value & $\mathrm{cm}$ \\
\hline be_lwp & Liquid water path best-estimate value & $\mathrm{g} / \mathrm{m}^{\wedge} 2$ \\
\hline cloud_base_height & Cloud base height & km AGL \\
\hline surface_temp & Surface temperature & $\mathrm{K}$ \\
\hline qc_surface_temp & $\begin{array}{l}\text { Quality check results on field: Surface } \\
\text { temperature }\end{array}$ & unitless \\
\hline surface_vapor_pres & Surface vapor pressure & $\mathrm{kPa}$ \\
\hline qc_surface_vapor_pres & $\begin{array}{l}\text { Quality check results on field: Surface vapor } \\
\text { pressure }\end{array}$ & unitless \\
\hline surface_pres & Surface pressure & $\mathrm{kPa}$ \\
\hline qc_surface_pres & Quality check results on field: Surface pressure & unitless \\
\hline surface_rh & Surface relative humidity & $\%$ \\
\hline qc_surface_rh & $\begin{array}{l}\text { Quality check results on field: Surface relative } \\
\text { humidity" }\end{array}$ & unitless \\
\hline tbsky23 & Sky brightness temperature at $23.8 \mathrm{GHz}$ & $\mathrm{K}$ \\
\hline qc_tbsky23 & $\begin{array}{l}\text { Quality check results on field: Sky brightness } \\
\text { temperature at } 23.8 \mathrm{GHz}\end{array}$ & unitless \\
\hline tbsky31 & Sky brightness temperature at $31.4 \mathrm{GHz}$ & $\mathrm{K}$ \\
\hline qc_tbsky31 & $\begin{array}{l}\text { Quality check results on field: Sky brightness } \\
\text { temperature at } 31.4 \mathrm{GHz}\end{array}$ & unitless \\
\hline orig_pwv & Total water vapor along LOS path & $\mathrm{cm}$ \\
\hline qc_orig_pwv & $\begin{array}{l}\text { Quality check results on field: Total water vapor } \\
\text { along LOS path }\end{array}$ & unitless \\
\hline orig_Iwp & Total liquid water along LOS path & $\mathrm{g} / \mathrm{m}^{\wedge} 2$ \\
\hline qc_orig_Iwp & $\begin{array}{l}\text { Quality check results on field: Total liquid water } \\
\text { along LOS path" }\end{array}$ & unitless \\
\hline tbsky23_nobias & $\begin{array}{l}\text { Sky brightness temperature at } 23.8 \mathrm{GHz} \text {, with } \\
\text { the bias removed }\end{array}$ & $\mathrm{K}$ \\
\hline
\end{tabular}


Table B.1: Output variables (cont.).

\begin{tabular}{|c|c|c|}
\hline Fieldname & Description & Units \\
\hline tbsky31_nobias & $\begin{array}{l}\text { Sky brightness temperature at } 31.4 \mathrm{GHz} \text {, with } \\
\text { the bias removed }\end{array}$ & $\mathrm{K}$ \\
\hline stat2_pwv & $\begin{array}{l}\text { Precipitable water vapor retrieved using } \\
\text { predicted mean radiating temperatures and } \\
\text { retrieval coefficients }\end{array}$ & $\mathrm{cm}$ \\
\hline stat2_pwv_uncertainty & $\begin{array}{l}\text { 1-sigma uncertainty in precipitable water vapor } \\
\text { retrieved using the stat } 2 \text { approach }\end{array}$ & $\mathrm{cm}$ \\
\hline qc_stat2_pwv & $\begin{array}{l}\text { Quality check results on field: Precipitable } \\
\text { water vapor retrieved using predicted mean } \\
\text { radiating temperatures and retrieval coefficients }\end{array}$ & unitless \\
\hline stat2_Iwp & $\begin{array}{l}\text { Cloud liquid water path retrieved using predicted } \\
\text { mean radiating temperatures and retrieval } \\
\text { coefficients }\end{array}$ & $\mathrm{g} / \mathrm{m}^{\wedge} 2$ \\
\hline stat2_Iwp_uncertainty & $\begin{array}{l}\text { 1-sigma uncertainty in cloud liquid water path } \\
\text { retrieved using the stat2 approach }\end{array}$ & $\mathrm{g} / \mathrm{m}^{\wedge} 2$ \\
\hline qc_stat2_lwp & $\begin{array}{l}\text { Quality check results on field: Cloud liquid } \\
\text { water path retrieved using predicted mean } \\
\text { radiating temperatures and retrieval coefficients }\end{array}$ & unitless \\
\hline stat2_tliq_flag & Status flag associated with stat2 retrievals & unitless \\
\hline tbsky23_calculated & $\begin{array}{l}\text { Calculated sky brightness temperature at } \\
23.8 \mathrm{GHz}\end{array}$ & $\mathrm{K}$ \\
\hline tbsky31_calculated & $\begin{array}{l}\text { Calculated sky brightness temperature at } \\
31.4 \mathrm{GHz}\end{array}$ & $\mathrm{K}$ \\
\hline phys_pwv & $\begin{array}{l}\text { Precipitable water vapor retrieved using a } \\
\text { physical/iterative approach }\end{array}$ & $\mathrm{cm}$ \\
\hline qc_phys_lwp & $\begin{array}{l}\text { Quality check results on field: Precipitable } \\
\text { water vapor retrieved using a physical/iterative } \\
\text { approach }\end{array}$ & unitless \\
\hline phys_lwp & $\begin{array}{l}\text { Cloud liquid water path retrieved using a } \\
\text { physical/iterative approach }\end{array}$ & $\mathrm{g} / \mathrm{m}^{\wedge} 2$ \\
\hline qc_phys_lwp & $\begin{array}{l}\text { Quality check results on field: Cloud liquid } \\
\text { water path retrieved using a physical/iterative } \\
\text { approach }\end{array}$ & unitless \\
\hline phys_pwv_uncertainty & $\begin{array}{l}\text { 1-sigma uncertainty in precipitable water vapor } \\
\text { retrieved using a physical/iterative approach }\end{array}$ & $\mathrm{cm}$ \\
\hline phys_Iwp_uncertainty & $\begin{array}{l}\text { 1-sigma uncertainty in cloud liquid water path } \\
\text { retrieved using a physical/iterative approach }\end{array}$ & $\mathrm{g} / \mathrm{m}^{\wedge} 2$ \\
\hline phys_niter & $\begin{array}{l}\text { Number of iterations needed by the physical } \\
\text { retrieval for convergence }\end{array}$ & counts \\
\hline phys_rms & $\begin{array}{l}\text { Root mean square difference between the } \\
\text { computed and observed brightness } \\
\text { temperatures for the last iteration }\end{array}$ & $\mathrm{K}$ \\
\hline phys_converge & Convergence value for the physical retrieval & arbitrary \\
\hline sonde_times & $\begin{array}{l}\text { Flag indicating when the sonde launches } \\
\text { occurred }\end{array}$ & unitless \\
\hline
\end{tabular}


Table B.1: Output variables (cont.).

\begin{tabular}{|c|c|c|}
\hline Fieldname & Description & Units \\
\hline sonde_pwv & $\begin{array}{l}\text { Precipitable water vapor integrated from the } \\
\text { radiosonde profile }\end{array}$ & $\mathrm{cm}$ \\
\hline mean_pwv_mwr & $\begin{array}{l}\text { Ensemble average for MWR vapor in window } \\
\text { centered upon current sample }\end{array}$ & $\mathrm{cm}$ \\
\hline sdev_pwv_mwr & $\begin{array}{l}\text { Standard deviation of ensemble average for } \\
\text { MWR vapor }\end{array}$ & $\mathrm{cm}$ \\
\hline num_pwv_mwr & $\begin{array}{l}\text { Size of MWR ensemble for mean_pwv_mwr } \\
\text { field }\end{array}$ & unitless \\
\hline mean_lwp_mwr & $\begin{array}{l}\text { Ensemble average for MWR liquid in window } \\
\text { centered upon current sample }\end{array}$ & $\mathrm{g} / \mathrm{m}^{\wedge} 2$ \\
\hline sdev_Iwp_mwr & $\begin{array}{l}\text { Standard deviation of ensemble average for } \\
\text { MWR liq }\end{array}$ & $\mathrm{g} / \mathrm{m}^{\wedge} 2$ \\
\hline num_Iwp_mwr & Size of MWR ensemble for mean_Iwp_mwr field & unitless \\
\hline mean_tbsky23_mwr & $\begin{array}{l}\text { Ensemble average for MWR } 23.8 \mathrm{GHz} \text { sky } \\
\text { brightness temperature in window centered } \\
\text { upon current sample }\end{array}$ & $\mathrm{K}$ \\
\hline sdev_tbsky23_mwr & $\begin{array}{l}\text { Standard deviation for ensemble average for } \\
\text { MWR } 23.8 \mathrm{GHz} \text { sky brightness temperature }\end{array}$ & $\mathrm{K}$ \\
\hline num_tbsky23_mwr & $\begin{array}{l}\text { Size of MWR ensemble for mean_tbsky23_mwr } \\
\text { field }\end{array}$ & unitless \\
\hline mean_tbsky31_mwr & $\begin{array}{l}\text { Ensemble average for MWR } 31.4 \mathrm{GHz} \text { sky } \\
\text { brightness temperature in window centered } \\
\text { upon current sample }\end{array}$ & $\mathrm{K}$ \\
\hline sdev_tbsky31_mwr & $\begin{array}{l}\text { Standard deviation for ensemble average for } \\
\text { MWR } 31.4 \mathrm{GHz} \text { sky brightness temperature }\end{array}$ & $\mathrm{K}$ \\
\hline num_tbsky31_mwr & $\begin{array}{l}\text { Size of MWR ensemble for mean_tbsky23_mwr } \\
\text { field }\end{array}$ & unitless \\
\hline vbias_yyyymmdd & Variable bias date & $\begin{array}{l}\text { YYYYMMDD } \\
\text { [UTC] }\end{array}$ \\
\hline vbias_hour & Variable bias hour & hour [UTC] \\
\hline vbias_23 & Variable bias offset at $23.8 \mathrm{GHz}$ & $\mathrm{K}$ \\
\hline vbias_31 & Variable bias offset at $31.4 \mathrm{GHz}$ & $\mathrm{K}$ \\
\hline lat & north latitude & degrees \\
\hline Ion & east longitude & degrees \\
\hline alt & altitude & altitude \\
\hline
\end{tabular}

